\title{
Diferenças entre bananas de cultivares Prata e Nanicão ao longo do amadurecimento: características físico-químicas e compostos voláteis
}

\author{
Differences between Prata and Nanicão banana cultivars during ripening: \\ physicochemical characteristics and volatile compounds
}

\author{
Baraquizio Braga do NASCIMENTO JUNIOR ${ }^{1 \star}$, Leonardo Peçanha OZORIO², Claudia Moraes REZENDE², \\ Antônio Gomes SOARES ${ }^{3}$, Marcos José de Oliveira FONSECA ${ }^{3}$
}

\section{Resumo}

Bananas verdes [Nanicão (Musa sp., subgrupo Cavendish) e Prata (Musa sp., subgrupo Prata)] foram estudadas durante o seu amadurecimento. As propriedades físicas (firmeza), físico-químicas ( $\mathrm{pH}$, acidez total titulável e sólidos solúveis) e químicas (açúcares, compostos fenólicos e voláteis) foram analisadas e demonstraram diferenças significantes $(\mathrm{p} \leq 0,05)$ entre as bananas. A banana Prata apresentou valores mais altos de compostos fenólicos, sólidos solúveis, açúcares e firmeza do que a banana Nanicão. O método de coleta e análise dos compostos voláteis foram o headspace em dedo frio e a cromatografia gasosa. Os ésteres acetatos, butiratos, isobutiratos e isovaleratos foram predominantes. A banana Prata produziu maiores concentrações de voláteis do que a Nanicão, exceto para os acetatos. O comportamento das curvas de produção dos ésteres seguiu um aumento contínuo, até um pico, para em seguida apresentar uma diminuição no estágio de escurecimento das cascas dos frutos.

Palavras-chave: bananas; amadurecimento; voláteis; cromatografia gasosa; avaliação quantitativa.

\begin{abstract}
Fresh green bananas [Nanicão (Musa sp., subgroup Cavendish) and Prata (Musa sp., subgroup Prata)] were studied during their ripening. Physical (firmness), physicochemical ( $\mathrm{pH}$, total titrable acidity and soluble solids) and chemical properties (sugars, phenolics and volatile compounds) were analyzed and showed significant differences $(\mathrm{p} \leq 0.05)$. Prata presented higher values of phenolic compounds, soluble solids, sugars and firmness than Nanicão. A method to quantify the emission of esters was developed by cryogenic headspace and gas chromatography. Acetates, butyrates, isobutyrates and isovalerates were predominant. Prata produced a higher volatile concentration than Nanicão, except for acetates. In most cases, the amount of volatiles increased continuously until peel browning, followed by a decrease or a plateau.
\end{abstract}

Keywords: bananas; ripening; volatiles; gas chromatography; quantitative evaluation.

\section{Introdução}

As bananas Prata (subgrupo Prata) e Nanicão (subgrupo Cavendish) pertencem ao gênero Musa sp., da família Musaceae e são as mais produzidas no Brasil. A cultivar Prata é a mais consumida no país e a Nanicão, a mais aceita no mercado mundial (IBGE, 2007). Muito apreciada no Brasil e no mundo, a banana é a quarta cultura agrícola mais importante do planeta, ficando atrás apenas do arroz, do trigo e do milho e apresentando o maior volume de produção mundial. O Brasil é o segundo maior produtor mundial de banana, com uma produção de 7,1 milhões de toneladas em 2006, em uma área de 507,7 mil hectares, cerca de $10 \%$ da produção mundial, atrás apenas da Índia (ONU, 2006).

Durante o amadurecimento da banana, muitas transformações físicas, físico-químicas e químicas que ocorrem, são importantes para monitorar o processo de amadurecimentos dos frutos e caracterizar os estágios de maturação: a firmeza diminui acompanhada por uma mudança na coloração da casca devido à degradação da clorofila e à síntese de carotenóides. $\mathrm{O}$ teor de sólidos solúveis aumenta, atingindo valores de até $27 \%$; a acidez normalmente aumenta até atingir um máximo, quando a casca está totalmente amarela, para depois decrescer, predominando o ácido málico. $\mathrm{O}$ amido é degradado rapidamente, com o acúmulo de açúcares. A adstringência, representada pela presença de taninos, decresce à medida que o fruto vai amadurecendo, podendo também variar com a época de colheita do fruto (LICHTEMBERG, 1999).

$\mathrm{O}$ aroma característico da banana também se intensifica com o amadurecimento, sendo um importante contribuinte para a qualidade dos frutos e influencia a aceitabilidade do consumidor. Bananas produzem durante o amadurecimento substâncias voláteis importantes para o aroma, tais como: ésteres, álcoois, aldeídos, cetonas, aminas e fenóis; sendo principalmente os

Recebido para publicação em 3/5/2007

Aceito para publicação em 18/9/2007 (002500)

${ }^{1}$ Departamento de Química e Exatas, Universidade Estadual do Sudoeste da Bahia - UESB, CEP 45206-190, Jequié - BA, Brasil, E-mail: barab@uesb.br

${ }^{2}$ Departamento de Química Orgânica, Instituto de Química, Universidade Federal do Rio de Janeiro - UFRJ, CEP 21945-970, Rio de Janeiro - RJ, Brasil

3 Empresa Brasileira de Pesquisa Agropecuária, CEP 23020-470, Rio de Janeiro - RJ, Brasil

${ }^{*}$ A quem a correspondência deve ser enviada 
ésteres o grupo de substâncias voláteis mais importantes que contribuem para o odor característico da fruta (MORTON; MACLEOD, 1990).

Estão descritas na literatura diferentes variações no comportamento dos ésteres durante o amadurecimento das bananas. Tressl e Jennings (1972) monitoraram os acetatos e butiratos da cultivar Valerie, originária da América Central, por headspace dinâmico num período de 12 dias. Foi observada uma produção cíclica e fora de fase entre os voláteis. Mattei (1973) e Mattei e Paillard (1973) estudaram os voláteis de bananas Musa Cavendish em diferentes temperaturas de armazenamento $\left(12\right.$ a $\left.30^{\circ} \mathrm{C}\right)$. A concentração dos voláteis cresceu numa taxa fixa até um máximo, seguida de uma forte diminuição no estágio de coloração 7, quando o fruto se encontrava totalmente amarelado com pequenas áreas escuras. Macku e Jennings (1987) relataram também, com a cultivar Valerie, que a concentração dos voláteis aumentou continuamente até o início do escurecimento da casca, porém apenas uma suave queda foi observada. A única exceção a este comportamento foi do acetato de etila, que aumentou até o período de senescência. Foi observada uma correlação linear entre a razão total de ésteres acetato e butirato com o tempo de amadurecimento do fruto.

Frente ao contraste entre a importância da cultura da banana no território brasileiro e a escassez de dados de acompanhamento do amadurecimento das cultivares de maior destaque econômico no país, este trabalho visa avaliar as principais características físico-químicas e dos compostos voláteis das cultivares de bananas Prata e Nanicão cultivadas no Estado do Rio de Janeiro. Foram avaliados firmeza, $\mathrm{pH}$, acidez total titulável, compostos fenólicos, sólidos solúveis, açúcares e a evolução quantitativa dos ésteres voláteis por cromatografia em fase gasosa e cromatografia a gás acoplada a espectrometria de massas por um período de 14 dias.

\section{Material e métodos}

\subsection{Frutos}

Bananas da cultivar Nanicão (Musa sp., subgrupo Cavendish), pesando entre 90 a 290 g, comprimento de 15 a $26 \mathrm{~cm}$, e bananas da cultivar Prata (Musa sp., subgrupo Prata), pesando entre 87 a $250 \mathrm{~g}$, comprimento de 12 a $22 \mathrm{~cm}$, verdes e maduras fisiologicamente (completamente desenvolvidas), foram climatizadas comercialmente pelo produtor com $1000 \mu \mathrm{L} . \mathrm{L}^{-1}$ de etileno (uma mistura de $95 \%$ de nitrogênio e 5\% de etileno) a um fluxo de $41,7 \mathrm{~mL} /$ hora por 24 horas a $15^{\circ} \mathrm{C}$, em câmara de condicionamento, a uma umidade relativa de $85 \%$. As bananas foram obtidas da Associação dos Produtores de Banana da cidade de Cachoeiras de Macacú no Estado do Rio de Janeiro - RJ, Brasil, localizada à latitude $22,5^{\circ}$ sul, longitude $42,8^{\circ}$ oeste e altitude de 62 m (IBGE, 2007). Após a climatização, as bananas foram transportadas para o laboratório para instalação dos experimentos.

De um lote proveniente de 8 caixas de cada cultivar de banana (20 kg por caixa), selecionaram-se visualmente os frutos verdes de maturidade próxima, descartando-se aqueles que estavam fora do padrão (injuriados e amassados). As bananas foram constituídas de buquês com 6 frutos cada e estes armazenados a uma temperatura de $24^{\circ} \mathrm{C} \pm 2$ e umidade relativa de $78,5 \%$ durante as análises.

Quando as bananas foram consideradas totalmente maduras, isto é, quando as cascas estavam totalmente amareladas com pequenas áreas manchadas e amarronzadas (coloração estágio 7), de acordo com o sistema de classificação de bananas da Embrapa, todas as análises foram concluídas (MATSUURA; FOLEGATTI, 2001).

\subsection{Análises físico-químicas}

Os experimentos físico-químicos foram realizados com 4 repetições para cada análise, iniciados 2 dias após a colheita dos frutos (frutos verdes - estágio de coloração 1), correspondente ao período de transporte até a chegada ao Laboratório de Pós-Colheita da Embrapa (Agroindústria de Alimentos do Rio de Janeiro, Brasil) e finalizados no $14^{\circ}$ dia (frutos totalmente amarelos com pequenas áreas manchadas e amarronzadas estágio de coloração 7).

Firmeza, $p H$, acidez total titulável, compostos

fenólicos, sólidos solúveis e açúcares

A firmeza dos frutos foi determinada por ensaios de penetração na fruta inteira, utilizando o texturômetro da marca Stable Micro Systems (Surrey, UK), modelo TA XT2i, com probe cilíndrico de aço inoxidável com diâmetro de $6 \mathrm{~mm}$. As bananas descascadas foram colocadas sob o probe e foram realizadas quatro penetrações na parte central da banana, do mesmo lado. A profundidade de cada penetração foi de $12 \mathrm{~mm}$, à velocidade de $2,0 \mathrm{~mm} \mathrm{seg}^{-1}$. Os resultados foram expressos em Newton $(\mathrm{N})$.

Para a análise de $\mathrm{pH}, 10 \mathrm{~g}$ das polpas das bananas foram picadas e misturadas em um mixer com $40 \mathrm{~mL}$ de água deionizada. $\mathrm{O}$ pH foi medido utilizando-se um pHmetro da marca Schott Handylab (Jena, Alemanha), modelo CG 842.

A acidez total titulável foi determinada por titulação com solução de hidróxido de sódio $(\mathrm{NaOH}) 0,1 \mathrm{~N}$ e indicador fenolftaleína, até atingir $\mathrm{pH} 8,0$. Os resultados foram expressos em \% de ácido málico em $100 \mathrm{~g}$ de polpa.

Os compostos fenólicos foram extraídos e dosados de acordo com a técnica padronizada por Goldstein e Swain (1963), com algumas modificações. $\mathrm{O}$ ácido tânico presente em $30 \mathrm{~g}$ de bananas foi extraído com $500 \mathrm{~mL}$ de metanol a $80 \%$ p/v, em 4 extrações sucessivas. Após as extrações, a solução foi transferida para balões volumétricos de $500 \mathrm{~mL}$. Pipetou-se $5 \mathrm{~mL}$ da solução e transferiu-se para balões volumétricos de $20 \mathrm{~mL}$. Adicionou-se $5 \mathrm{~mL}$ do reagente de Folin-Denis. Na determinação foi utilizado o método de Folin-Denis, conforme AOAC (1992), e a leitura foi realizada em espectrofotômetro Varian Cary 50 probe (EUA) a $760 \mathrm{~nm}$, com sistema computadorizado, sendo os resultados expressos em g de ácido tânico/100 g de polpa.

Os sólidos solúveis foram determinados por refratometria em aparelho digital da marca ATAGO (EUA), modelo PR-100, 
com compensação de temperatura automática a $25^{\circ} \mathrm{C}$ e os resultados expressos em ${ }^{\circ}$ Brix.

Os açúcares foram analisados por cromatografia em fase líquida de alta eficiência (Shimadu SIL-9A, Áustria), com detector de refratometria (Beckman 156 RID, Suécia), de acordo com o método proposto por Mollá et al. (1994). Cinco g da polpa das bananas foram misturados com $40 \mathrm{~mL}$ de ácido tricloroacético $(4 \% \mathrm{p} / \mathrm{v})$. Após a centrifugação $(13200 \mathrm{rpm}$ por 10 minutos, a $\left.5{ }^{\circ} \mathrm{C}\right), 0,2 \mathrm{~mL}$ do sobrenadante foi misturado com $0,8 \mathrm{~mL}$ de manitol $\left(0,4 \mathrm{~g} 100 \mathrm{~mL}^{-1}\right)$. A amostra foi filtrada em uma membrana Millipore HAWP 02500 e injetada em uma coluna Spherisorb $\mathrm{NH}_{2}$ (Merck, EUA) $5 \mu \mathrm{m}$ esférica de $25 \mathrm{~cm}$, utilizando-se as seguintes condições: fase móvel água/acetonitrila (25:75), taxa de fluxo $1 \mathrm{~mL} \cdot \mathrm{min}^{-1}$ e temperatura do forno de $35^{\circ} \mathrm{C}$. O volume injetado foi de $25 \mu \mathrm{L}$ e os resultados expressos em g por $100 \mathrm{~g}$ de polpa.

\subsection{Amostragem dos voláteis pela técnica de headspace em "dedo frio"}

Os experimentos foram iniciados a partir do $5^{\circ}$ dia após a colheita dos frutos, em triplicatas e finalizados no $14^{\circ}$ dia. A coleta dos compostos voláteis foi realizada por headspace em "dedo frio".

Para a determinação dos voláteis, $700 \mathrm{~g}$ de polpa das bananas Prata e Nanicão amassadas foram transferidas separadamente para frascos erlenmeyers de $2 \mathrm{~L}$, com boca esmerilhada, fechados com um recipiente cilíndrico de vidro contendo gelo seco ("dedo frio"). Estes frascos foram colocados em um banho de água à temperatura de $22{ }^{\circ} \mathrm{C} \pm 2$ (a uma altura de $10 \mathrm{~cm}$ da base).

A camada de cristais formada na superfície do "dedo frio" foi raspada com espátula a cada 20 minutos, por um período de 4 horas, para dentro de um bécher e lavada com $1 \mathrm{~mL}$ de $\mathrm{CH}_{2} \mathrm{Cl}_{2}$ (Tédia, EUA), pureza grau resíduo de pesticida. O material coletado foi transferido para um recipiente hermeticamente fechado e guardado em freezer a $0{ }^{\circ} \mathrm{C}$. Após 4 horas, o extrato coletado foi tratado com $3 \mathrm{~g}$ de $\mathrm{NaCl}$, a fim de quebrar a emulsão formada entre a fase orgânica e a água. Após esse tratamento, $\mathrm{o}$ extrato orgânico foi seco com $4 \mathrm{~g}$ de $\mathrm{Na}_{2} \mathrm{SO}_{4}$ anidro. A amostra isenta de água foi transferida para um balão volumétrico, concentrada com um fluxo de nitrogênio de $0,6 \mathrm{~mL} \mathrm{seg}^{-1}$ até $1 \mathrm{~mL}$ e adicionado o padrão interno $n$-octanoato de etila (Aldrich, EUA) na concentração de $100 \mu \mathrm{L}_{\text {L }}{ }^{-1}$ e ajustado com $\mathrm{CH}_{2} \mathrm{Cl}_{2} \mathrm{em}$ balança analítica até o peso de 1,20 g.

\subsection{Cromatografia em fase gasosa acoplada à espectrometria de massas (CG-EM) e cromatografia em fase gasosa com detector de ionização por chama (CG-DIC)}

A análise por CG-EM foi realizada em um instrumento Agilent 5973 (Palo Alto, EUA), com impacto de elétrons a $70 \mathrm{eV}$, coluna DB-1 metilpolisiloxano (30 m x 0,25 mm x 1,0 $\mu \mathrm{m}$; Hewlett Packard Co., PA, EUA), modo de injeção sem divisão de fluxo por meio minuto, gás carreador hélio, pressão constante de 4,5 psi, temperatura do injetor de $240{ }^{\circ} \mathrm{C}$ e temperatura da linha de transferência de $280^{\circ} \mathrm{C}$. Programação de temperatura: temperatura inicial de $35^{\circ} \mathrm{C}$ por 8 minutos, rampa de aquecimento de $3{ }^{\circ} \mathrm{C} \min ^{-1}$ até $150{ }^{\circ} \mathrm{C}$ e isoterma de 5 minutos.

A análise por CG-DIC foi realizada num instrumento HP-5890 (Hewlett Packard Co., PA, EUA), com detector de ionização por chama (DIC), coluna HP-1 de fase estacionária metilpolisiloxano $(30 \mathrm{~m} \times 0,25 \mathrm{~mm} \times 1,0 \mu \mathrm{m})$, modo de injeção sem divisão de fluxo por meio minuto, gás carreador hidrogênio, pressão de 14 psi, temperatura do injetor de $240^{\circ} \mathrm{C}$, temperatura do detector de $280^{\circ} \mathrm{C}$, programação de temperatura: temperatura inicial de $35^{\circ} \mathrm{C}$ por 8 minutos, rampa de aquecimento de $3{ }^{\circ} \mathrm{C} \mathrm{min}^{-1}$ até $150{ }^{\circ} \mathrm{C}$ e isoterma de 5 minutos.

Foi injetado $1 \mu \mathrm{L}$ dos extratos de cada banana e suas repetições. Os ésteres presentes nas amostras foram identificados pela comparação direta dos tempos de retenção com os padrões sintetizados e pela fragmentação de seus espectros de massas.

A técnica adotada para a quantificação dos ésteres foi a padronização interna, realizada em triplicata. Foram preparadas 9 soluções padrão de concentrações conhecidas para cada éster de interesse, nas faixas de 0,04 a 405,14 $\mu \mathrm{L} . \mathrm{L}^{-1}$, nas quais foi adicionado o padrão interno $n$-octanoato de etila (Aldrich, EUA) na concentração de $100 \mu \mathrm{L} . \mathrm{L}^{-1}$.

A concentração dos voláteis na banana foi calculada pela razão entre as áreas integradas dos ésteres, obtidos das injeções de $1 \mu \mathrm{L}$ das amostras, adicionados ao padrão interno de concentração conhecida (100 $\left.\mu \mathrm{L}^{\mathrm{L}} \mathrm{L}^{-1}\right)$; com as áreas integradas dos padrões da curva de calibração de concentrações conhecidas, adicionadas também ao padrão interno na mesma concentração. Desta forma, com o peso final de $1 \mathrm{~mL}$ do headspace e o peso das amostras dos frutos, era calculada a produção de cada composto $\left(\mu \mathrm{g} \cdot \mathrm{kg}^{-1}\right)$.

\subsection{Síntese dos padrões}

Os ésteres acetatos de etila, butila, isoamila e isobutila; butiratos de etila, butila, isoamila e isobutila; isobutiratos de isobutila, butila e isoamila; e isovaleratos de etila, butila, isobutila e isoamila foram sintetizados via reação de Fischer (VOGEL, 1989). A natureza dos ésteres e seu grau de pureza (todos acima de $95 \%$ por CG) foram avaliados por espectrometria de ressonância magnética de ${ }^{1} \mathrm{H}$ e ${ }^{13} \mathrm{C}$, espectrometria no infravermelho e CG-EM. Os ácidos carboxílicos e os álcoois utilizados foram obtidos da Merck (Alemanha) e Aldrich (EUA).

\subsection{Avaliação do método}

Para avaliar a metodologia analítica escolhida foram calculados os parâmetros analíticos de recuperação, linearidade, repetitividade, precisão, limites de detecção e quantificação, de acordo com Ribani et al. (2004).

A linearidade do método foi avaliada através do coeficiente de correlação $\left(\mathrm{R}^{2}\right)$. Já a repetitividade foi representada pelo desvio padrão médio. Os Limites de Detecção (LD) e de quantificação (LQ) no CG-DIC foram determinados matematicamente através da relação entre o desvio padrão da curva de calibração e sua inclinação, usando-se os seguintes fatores de multiplicação (Equação 1): 
$L D=3,3 * \frac{s}{S} e L Q=10 * \frac{s}{S}$

em que $s$ é a estimativa do desvio padrão do coeficiente linear e $S$ é a inclinação ou coeficiente angular, ambos da curva analítica; estatisticamente mais confiáveis.

\subsection{Análise estatística}

Os resultados físico-químicos e dos compostos voláteis foram estatisticamente analisados pelo programa BIOESTAT 2.0, através da análise de variância (ANOVA), pelo teste de comparação de médias, utilizando-se os testes de Tukey, de $F$ (Fisher) e de $t$ Student todos com $\mathrm{p} \leq 0,05$, de acordo com Ayres et al. 2000).

\section{Resultados e discussão}

\subsection{Análises físico-químicas}

Na Tabela 1 estão apresentados os valores das análises de firmeza, pH, acidez total titulável, compostos fenólicos, sólidos solúveis e açúcares para as cultivares Prata e Nanicão.

As análises de firmeza para a banana Prata e Nanicão apresentaram um desvio padrão relativo médio de 1,5 e 1,1\%, respectivamente. Já o grau de confiança de $t$ Student, que relaciona em que intervalo de confiança encontra-se a média dos valores, foi de $\mathrm{X} \pm 0.001$, tanto para a banana Prata como para a Nanicão; em que $X$ representa a média das 4 repetições realizadas durante cada experimento dia-a-dia.

Observou-se um maior declínio da firmeza para a cultivar Nanicão comparada à cultivar Prata. Enquanto na banana Prata a queda mais acentuada aconteceu no $11^{\circ}$ dia após a colheita, na banana Nanicão essa queda ocorreu no $9^{\circ}$ dia após a colheita. A análise estatística realizada através do teste de comparação das médias pelo teste de Tukey com $\mathrm{p} \leq 0,05$ detectou diferenças significativas entre as cultivares dia-a-dia, durante o processo de amadurecimento. A diferença mais marcante foi verificada no $8^{\circ}$ dia após a colheita, quando foram encontrados os valores de 5,78 e 3,56 N para as cultivares de banana Prata e Nanicão, respectivamente.

De acordo com Cano et al. (1997), diferenças em firmeza podem ser relacionadas a diferentes quantidades de polissacarídeos, amido e substâncias pécticas encontradas nas polpas de bananas.

A perda de firmeza pelos frutos das bananas também pode ser um reflexo do aumento da umidade da polpa em razão de trocas osmóticas com a casca. Os açúcares da polpa aumentam mais rapidamente durante o amadurecimento do que os da casca, contribuindo para uma mudança diferencial na pressão osmótica. Além de perder água para a polpa, a casca da banana perde água para o meio ambiente, pela transpiração; dessa forma, observa-se um incremento da relação polpa/casca durante o amadurecimento. Tal relação é também conhecida como "coeficiente de amadurecimento", que é considerado um índice de maturidade (MATSUURA; FOLEGATTI, 2001).

A diminuição na firmeza observada para ambas as cultivares durante o amadurecimento é condizente com estudos de Imsabai, Ketsa e Van Doorn (2006), que realizaram estudos fisiológicos e bioquímicos com bananas de um cruzamento entre Musa x paradisíaca, do grupo genômico ABB e por Pinheiro (2004), que desenvolveu estudos com a cultivar de banana-maçã.

As análises de $\mathrm{pH}$ apresentaram um desvio padrão relativo médio de 0,63 e 0,27\%, para a cultivar Prata e Nanicão, respectivamente. Já o grau de confiança de $t$ Student, foi de $\mathrm{X} \pm 0,003$ para a banana Prata e $\mathrm{X} \pm 0,004$ para a banana Nanicão.

Diferenças significativas nos valores de $\mathrm{pH}$ entre as cultivares dia-a-dia foram observadas ao longo do amadurecimento, como pode ser visto na Tabela 1. A diferença mais marcante foi verificada no $9^{\circ}$ dia após a colheita, quando foram encontrados

Tabela 1. Valores das análises físico-químicas durante o amadurecimento para as cultivares Prata e Nanicão.

\begin{tabular}{|c|c|c|c|c|c|c|c|c|c|c|c|}
\hline & \multicolumn{11}{|c|}{ Banana Prata } \\
\hline & \multicolumn{11}{|c|}{ Dia } \\
\hline & 2 & 5 & 6 & 7 & 8 & 9 & 10 & 11 & 12 & 13 & 14 \\
\hline Firmeza & $15,12^{\mathrm{a}}$ & $10,09^{\mathrm{a}}$ & $7,12^{\mathrm{a}}$ & $5,78^{a}$ & $5,78^{a}$ & $4,89^{\mathrm{a}}$ & $4,00^{\mathrm{a}}$ & $3,56^{\mathrm{a}}$ & $3,56^{\mathrm{a}}$ & $3,56^{\mathrm{a}}$ & $3,56^{\mathrm{a}}$ \\
\hline $\mathrm{pH}$ & $4,60^{\mathrm{a}}$ & $4,58^{\mathrm{a}}$ & $4,49^{\mathrm{a}}$ & $4,49^{\mathrm{a}}$ & $4,27^{\mathrm{a}}$ & $4,16^{\mathrm{a}}$ & $4,06^{\mathrm{a}}$ & $4,06^{\mathrm{a}}$ & $4,06^{\mathrm{a}}$ & $4,06^{\mathrm{a}}$ & $4,06^{\mathrm{a}}$ \\
\hline Acid. tot. titul. & $0,17^{\mathrm{a}}$ & $0,17^{\mathrm{a}}$ & $0,25^{\mathrm{a}}$ & $0,72^{\mathrm{a}}$ & $0,72^{\mathrm{a}}$ & $0,78^{\mathrm{a}}$ & $0,66^{\mathrm{a}}$ & $0,66^{\mathrm{a}}$ & $0,66^{\mathrm{a}}$ & $0,66^{\mathrm{a}}$ & $0,66^{\mathrm{a}}$ \\
\hline Comp. fenólicos & $0,057^{\mathrm{a}}$ & $0,036^{\mathrm{a}}$ & $0,032^{\mathrm{a}}$ & $0,026^{\mathrm{a}}$ & $0,017^{\mathrm{a}}$ & $0,011^{\mathrm{a}}$ & $0,009^{\mathrm{a}}$ & $0,009^{\mathrm{a}}$ & $0,009^{a}$ & $0,009^{a}$ & $0,009^{\mathrm{a}}$ \\
\hline SS. & $0,95^{\mathrm{a}}$ & $8,06^{\mathrm{a}}$ & $12,18^{\mathrm{a}}$ & $15,73^{\mathrm{a}}$ & $18,72^{\mathrm{a}}$ & $23,46^{\mathrm{a}}$ & $24,38^{\mathrm{a}}$ & $24,38^{\mathrm{a}}$ & $24,38^{\mathrm{a}}$ & $24,38^{a}$ & $24,38^{\mathrm{a}}$ \\
\hline \multirow[t]{2}{*}{ Açúcares } & $0,20^{\mathrm{a}}$ & $11,59^{\mathrm{a}}$ & $13,91^{\mathrm{a}}$ & $15,77^{\mathrm{a}}$ & $17,06^{\mathrm{a}}$ & $18,95^{\mathrm{a}}$ & $20,11^{\mathrm{a}}$ & $20,11^{\mathrm{a}}$ & $20,11^{\mathrm{a}}$ & $20,11^{\mathrm{a}}$ & $20,11^{\mathrm{a}}$ \\
\hline & \multicolumn{11}{|c|}{ Banana Nanicão } \\
\hline Firmeza & $13,34^{\mathrm{b}}$ & $8,27^{b}$ & $6,67^{b}$ & $4,45^{\mathrm{b}}$ & $3,56^{\mathrm{b}}$ & $3,11^{b}$ & $3,11^{b}$ & $3,11^{b}$ & $3,11^{b}$ & $3,11^{b}$ & $3,11^{\mathrm{b}}$ \\
\hline $\mathrm{pH}$ & $5,14^{\mathrm{b}}$ & $5,07^{\mathrm{b}}$ & $5,05^{\mathrm{b}}$ & $4,96^{\mathrm{b}}$ & $4,76^{\mathrm{b}}$ & $4,76^{\mathrm{b}}$ & $4,53^{\mathrm{b}}$ & $4,53^{\mathrm{b}}$ & $4,53^{\mathrm{b}}$ & $4,53^{\mathrm{b}}$ & $4,53^{\mathrm{b}}$ \\
\hline Acid. tot. titul. & $0,27^{b}$ & $0,31^{b}$ & $0,33^{\mathrm{b}}$ & $0,33^{\mathrm{b}}$ & $0,36^{\mathrm{b}}$ & $0,48^{\mathrm{b}}$ & $0,32^{b}$ & $0,32^{\mathrm{b}}$ & $0,32^{\mathrm{b}}$ & $0,32^{b}$ & $0,32^{\mathrm{b}}$ \\
\hline Comp. fenólicos & $0,032^{\mathrm{b}}$ & $0,027^{\mathrm{b}}$ & $0,024^{\mathrm{b}}$ & $0,020^{\mathrm{b}}$ & $0,015^{\mathrm{a}}$ & $0,012^{\mathrm{a}}$ & $0,008^{\mathrm{a}}$ & $0,006^{\mathrm{b}}$ & $0,004^{\mathrm{b}}$ & $0,004^{\mathrm{b}}$ & $0,004^{\mathrm{b}}$ \\
\hline SS. & $0,81^{\mathrm{a}}$ & $6,86^{\mathrm{b}}$ & $10,42^{\mathrm{b}}$ & $13,93^{\mathrm{b}}$ & $17,13^{\mathrm{b}}$ & $22,3^{\mathrm{b}}$ & $23,35^{\mathrm{b}}$ & $23,35^{\mathrm{b}}$ & $23,35^{\mathrm{b}}$ & $23,35^{\mathrm{b}}$ & $23,35^{\mathrm{b}}$ \\
\hline Açúcares & $0,17^{\mathrm{a}}$ & $10,98^{\mathrm{b}}$ & $13,03^{\mathrm{b}}$ & $15,50^{\mathrm{b}}$ & $16,07^{\mathrm{b}}$ & $17,11^{\mathrm{b}}$ & $17,19^{\mathrm{b}}$ & $17,19^{\mathrm{b}}$ & $17,19^{\mathrm{b}}$ & $17,19^{\mathrm{b}}$ & $17,19^{\mathrm{b}}$ \\
\hline
\end{tabular}

Firmeza (N); acid. tot. titul. (acidez total titulável - \% de ácido málico por $100 \mathrm{~g}$ de polpa); comp. fenólicos (compostos fenólicos - g de ácido tânico por 100 g de polpa); SS (sólidos solúveis - ${ }^{\circ}$ Brix); açúcares ( $\mathrm{g}$ por $100 \mathrm{~g}$ de polpa). Os valores são as médias de 4 repetições. Diferentes letras para as mesmas propriedades físico-químicas indicam que os valores diferem estatisticamente $(\mathrm{p} \leq 0,05)$ pelo teste de Tukey entre as cultivares. 
os valores de 4,16 e 4,76 para as cultivares de banana Prata e Nanicão, respectivamente.

$\mathrm{O}$ pH da polpa da banana verde tende a oscilar entre 5,0 e 5,6, enquanto que para a fruta madura esse valor cai para 4,2 a 4,7 (MATSUURA; FOLEGATTI, 2001). Para as cultivares Prata e Nanicão, foi observado que o $\mathrm{pH}$ dos frutos verdes foi de 4,60 e 5,14, respectivamente, correspondente ao estágio de coloração 1 (frutos verdes), enquanto que ao longo do amadurecimento dos frutos os valores foram de 4,27 para a banana Prata e 4,76 para a banana Nanicão, correspondentes ao estágio de coloração 6 (frutos totalmente amarelos). Observou-se um maior declínio do $\mathrm{pH}$ para a cultivar Prata comparada à Nanicão. A partir do $10^{\circ}$ dia após a colheita não foram observadas alterações no $\mathrm{pH}$, permanecendo os valores de 4,06 para a banana Prata e 4,53 para a banana Nanicão.

O decréscimo do $\mathrm{pH}$ ao longo do amadurecimento é esperado. Esta diminuição costuma ser associada ao acúmulo de açúcar e de constituintes ácidos durante o amadurecimento dos frutos.

As análises de acidez total titulável para as cultivares de banana Prata e Nanicão apresentaram um desvio padrão relativo médio de 3,6 e 1,03\%, respectivamente. O grau de confiança de t Student foi de $\mathrm{X} \pm 0,008$ para a banana Prata e $\mathrm{X} \pm 0,003$ para a banana Nanicão.

A acidez total titulável, por sua vez, foi associada ao aumento da concentração de ácido málico para as cultivares Prata e Nanicão, conforme descrito na Tabela 1. As bananas Prata e Nanicão apresentaram no fruto verde valores de 0,17 e 0,27\% de ácido málico por $100 \mathrm{~g}$ de polpa, respectivamente. Já no fruto maduro os valores encontrados foram de 0,72 e $0,36 \%$ de ácido málico por $100 \mathrm{~g}$ de polpa para a banana Prata e Nanicão, respectivamente. De acordo com Bleinroth et al. (1992), a banana no estádio verde caracteriza-se por apresentar uma baixa acidez, aumentando com o decorrer do amadurecimento, até atingir um máximo, quando a casca está totalmente amarela, para posteriormente decrescer.

A diferença mais marcante na acidez entre as cultivares dia-a-dia foi verificada no $7^{\circ}$ dia após a colheita, quando foram encontrados os valores de 0,72 e $0,33 \%$ de ácido málico por $100 \mathrm{~g}$ de polpa para as cultivares de banana Prata e Nanicão, respectivamente.

Valores encontrados na literatura por Cano et al. (1997); Imsabai, Ketsa e Van Doorn (2006) e Pinheiro (2004) para acidez total titulável em banana oscilam entre 0,14 a $0,22 \%$ de ácido málico por $100 \mathrm{~g}$ de polpa para o fruto verde e 0,26 a $0,57 \%$ de ácido málico por $100 \mathrm{~g}$ de polpa para o fruto maduro. Os valores obtidos neste trabalho para a cultivar Prata madura, a partir do $8^{\circ}$ dia após a colheita são superiores, o que se reflete nos menores valores de $\mathrm{pH}$ observados para essa cultivar.

Observou-se uma maior concentração média de acidez para a cultivar Prata comparada à cultivar Nanicão. A partir do $10^{\circ}$ dia após a colheita, ambas as cultivares não apresentaram mais alterações, permanecendo os valores de $0,66 \%$ de ácido málico por $100 \mathrm{~g}$ de polpa do fruto para a cultivar Prata e 0,32\% de ácido málico por $100 \mathrm{~g}$ de polpa para a cultivar Nanicão.
As análises de compostos fenólicos para as cultivares de banana Prata e Nanicão apresentaram um desvio relativo médio de 2,07 e 1,97\%, respectivamente. O grau de confiança de $t$ Student foi de $\mathrm{X} \pm 0,001$, tanto para a banana Prata, como para a banana Nanicão.

As cultivares de bananas também exibiram diferenças significativas em termos de compostos fenólicos dia-a-dia. A cultivar Prata apresentou teores mais elevados. A diferença mais significativa foi verificada no $5^{\circ}$ dia após a colheita, quando foram encontrados os valores de 0,036 e 0,027 g de ácido tânico em 100 g de polpa para as cultivares de banana Prata e Nanicão, respectivamente (Tabela 1 ). Porém, não existiu diferença significativa neste parâmetro entre o $8^{\circ}$ ao $10^{\circ}$ dia.

O período de senescência, associado à ausência de alteração na concentração dos compostos fenólicos ocorreu em dias diferentes para as cultivares (diferença de 2 dias). Na banana Prata ocorreu no $10^{\circ}$ dia após a colheita e na banana Nanicão ocorreu no $12^{\circ}$ dia.

A polpa da banana verde é caracterizada por uma forte adstringência determinada pela presença de compostos fenólicos solúveis, principalmente os taninos. À medida que o fruto amadurece, ocorre a polimerização desses compostos, com conseqüente diminuição da adstringência (PINHEIRO, 2004).

Os experimentos de sólidos solúveis apresentaram um desvio padrão relativo médio de 2,3 e 1,6\% para a cultivar Prata e Nanicão, respectivamente. Já o grau de confiança de t Student foi de $\mathrm{X} \pm 0,12$ para a banana Prata e $\mathrm{X} \pm 0,05$ para a banana Nanicão.

A cultivar Prata apresentou valores de sólidos solúveis superiores aos da Nanicão, mantendo correlação com os valores de açúcares encontrados para ambas as cultivares. O teor de sólidos aumenta em decorrência da hidrólise do amido, precursor dos açúcares. Valores encontrados na literatura (CANO et al., 1997; IMSABAI; KETSA; VAN DOORN, 2006; PINHEIRO, 2004) para sólidos solúveis em banana oscilam entre 0,78 a $0,92 \%{ }^{\circ} \mathrm{Brix}$ para o fruto verde e 19,72 a $22,36 \%{ }^{\circ}$ Brix para o fruto maduro. Os valores aqui encontrados foram semelhantes. Diferenças significativas entre as cultivares dia-a-dia foram observadas ao longo do amadurecimento, com exceção do $2^{\circ}$ dia após a colheita. A diferença mais marcante foi notada no $7^{\circ}$ dia após a colheita, quando foram encontrados os valores de 15,73 e $13,93 \%{ }^{\circ} \mathrm{Brix}$ para a banana Prata e Nanicão, respectivamente. A partir do $10^{\circ}$ dia após a colheita, ambas as cultivares não apresentaram mais alterações, mantendo os valores de $24,38 \%{ }^{\circ}$ Brix para a cultivar Prata e $23,35 \%{ }^{\circ}$ Brix para a cultivar Nanicão.

As análises para os experimentos de açúcares apresentaram um desvio padrão relativo médio de 1,7 e 3,0\% para a cultivar Prata e Nanicão, respectivamente. Já o grau de confiança de t Student, foi de $\mathrm{X} \pm 0,03$ para a banana Prata e $\mathrm{X} \pm 0,04$ para a banana Nanicão.

Uma das mudanças mais notáveis que ocorrem durante o amadurecimento da polpa da banana é a hidrólise do amido e a subseqüente acumulação de açúcar (MACKU; JENNINGS, 1987). Na Tabela 1 é possível verificar os teores crescentes de açúcares ao longo do amadurecimento para as cultivares 
estudadas. A diferença mais marcante foi notada no $10^{\circ}$ dia após a colheita, quando os valores encontrados de açúcar para a cultivar Prata foram de 20,11 g por $100 \mathrm{~g}$ de polpa e 17,19 $\mathrm{g}$ por $100 \mathrm{~g}$ de polpa para a cultivar Nanicão. A partir do $10^{\circ}$ dia após a colheita não houve alteração nos teores.

Durante o amadurecimento dos frutos observa-se um acúmulo de açúcares solúveis, precursores dos ácidos orgânicos, com predominância do ácido málico, o que acarreta uma diminuição do $\mathrm{pH}$ ao longo do amadurecimento.

Analisando os dados físico-químicos para as cultivares Prata e Nanicão, concluímos que os níveis mais altos de açúcares da banana Prata acarretaram um maior aumento nos teores de sólidos solúveis e na acidez, levando a valores mais baixos de pH. Enquanto que a cultivar Nanicão, com níveis de açúcares mais reduzidos ao longo do amadurecimento, apresentou menor concentração de sólidos solúveis e acidez e, conseqüentemente, valores mais altos de $\mathrm{pH}$.

\subsection{Avaliação do método de extração e quantificação dos compostos voláteis}

Os resultados da porcentagem de recuperação basearam-se nas fortificações das amostras em três diferentes concentrações, abrangendo a faixa detectada nas amostras reais, realizadas em triplicata, e os resultados variaram na faixa de 40,04 a 47,62\%, tendo como recuperação média 41,78\%, com precisão de 4,33\%. Como o headspace em "dedo frio" é baseado no equilíbrio da distribuição do analito entre a fase estacionária e a amostra, uma eficiência de $100 \%$ nunca pode ser atingida. Van der Kooi e Noij (1994) analisaram poluentes em água por SPME (Micro Extração em Fase Sólida) e encontraram recuperações na faixa de 4 a 25\%. Spme e Ibáñez et al. (1998) também analisaram os compostos voláteis de bananas, mangas, morangos, amoras e framboesas e obtiveram recuperações variando de 10,7 a 45,3\% e desvios padrão relativos variando de 5,9 a 14,5\%. É importante ressaltar que os resultados obtidos neste trabalho foram repetitivos e consistentes e que se encontraram dentro dos intervalos aceitáveis para as análises de traços, que estão entre 40 a 120\%, com precisão de até $\pm 15 \%$, de acordo com Ribani et al. (2004); Brito, Amarante Junior e Polese (2003), validando o método de análise.

O método guardou excelente relação linear com o sinal analítico, denotado pelos valores do coeficiente de correlação $\mathrm{R}^{2}$. A média do $\mathrm{R}^{2}$ para os 15 ésteres escolhidos como representativos de ambas as cultivares foi de 0,997. Aplicando o teste de t Student, encontrou-se para $\mathrm{p} \leq 0,05$ que os $\mathrm{R}^{2}$ experimentais não diferiram estatisticamente de $\mathrm{R}^{2}=1,0$, comprovando a linearidade do método.

Os valores de repetitividade representados pelo desvio padrão médio de três repetições sucessivas para cada éster apresentaram valores baixos. O valor médio para os quinze ésteres foi de 0,22 , demonstrando a repetitividade do método. A precisão avaliada pelo desvio padrão relativo médio foi abaixo de $6 \%$, valor esse bem distante do valor de $20 \%$ considerado aceitável quando se trabalha, por exemplo, com análises de traços ou impurezas (RIBANI et al., 2004; WOOD, 1999), indicando, portanto, a boa precisão do método.
Os valores dos limites de detecção e quantificação encontrados pelo método para os quinze ésteres estudados variaram nas faixas de 0,001 a $0,013 \mu \mathrm{g} \cdot \mathrm{kg}^{-1}$, e 0,002 a 0,040 $\mu \mathrm{g} \cdot \mathrm{kg}^{-1}$, respectivamente. Estes resultados indicam que o método é suficientemente sensível para detectar e quantificar a presença dos ésteres em níveis baixos de concentração.

\subsection{Produção dos compostos voláteis durante o amadurecimento}

Foram encontrados álcoois, ácidos, aldeídos, cetonas, fenóis e especialmente os ésteres como constituintes majoritários no extrato volátil por CG-EM.

Quinze ésteres da classe dos acetatos, butiratos, isobutiratos e isovaleratos, importantes para o aroma da banana (MORTON; MACLEOD, 1990), foram escolhidos para monitorar quantitativamente o processo de amadurecimento.

As variações observadas na concentração dos ésteres, que neste estudo representaram cerca de $70 \%$ da área dos voláteis por CG para as cultivares Prata e Nanicão, são mostradas nas Figuras 1 a 4 .

A Figura 1 apresenta a flutuação na concentração dos acetatos para as cultivares Prata e Nanicão ao longo do amadurecimento. Pela análise estatística realizada através do teste de $t$ Student para $\mathrm{p} \leq 0,05$, foi detectada uma diferença quantitativa significativa na produção dos ésteres entre as cultivares dia-adia. A exceção ocorreu no $5^{\circ}$ e no $9^{\circ}$ dia para o acetato de etila, no $5^{\circ}$ dia para o acetato de isoamila e no $6^{\circ}, 10^{\circ}$ e $11^{\circ}$ dia para o acetato de isobutila. Notou-se ainda, que o acetato de butila e a isobutila são produzidos regularmente na cultivar Prata, enquanto que na banana Nanicão só começaram a ser produzidos no $6^{\circ}$ dia. A maior taxa de produção dos ésteres acetato durante $\mathrm{o}$ amadurecimento foi encontrada para a banana Nanicão.

Na Figura 2 observa-se o comportamento da produção dos butiratos para as cultivares Prata e Nanicão durante o período de amadurecimento. A análise estatística permitiu detectar diferenças quantitativas significativas na produção dos ésteres entre as cultivares dia-a-dia. A exceção ocorreu no $9^{\circ}$ e no $14^{\circ}$ dia para o butirato de etila, no $9^{\circ}, 10^{\circ}$ e $14^{\circ}$ dia para o butirato de butila e no $8^{\circ}$ dia para o butirato de isoamila. Perceberam-se ainda diferentes dias de surgimento dos butiratos de butila, isobutila e etila nas bananas Prata e Nanicão. Na cultivar Prata os butiratos de butila, isobutila e etila são produzidos regularmente; já na banana Nanicão começam a ser produzidos a partir do $6^{\circ}$ dia os butiratos de butila e isobutila, e no $7^{\circ}$ dia o butirato de etila. A maior concentração dos ésteres butirato durante o amadurecimento foi encontrada para a banana Prata. A exceção coube apenas ao butirato de etila, sendo que a banana Nanicão superou a Prata.

A Figura 3 mostra o comportamento dos isobutiratos para as cultivares Prata e Nanicão durante o período do amadurecimento. Observaram-se diferenças significativas na produção dos ésteres entre as cultivares dia-a-dia. A exceção ocorreu apenas para o isobutirato de isoamila no $8^{\circ}$ e no $9^{\circ}$ dia. Não foi observada a produção de isobutirato de butila na cultivar Nanicão; na cultivar Prata a produção de isobutirato de butila ocorreu apenas 

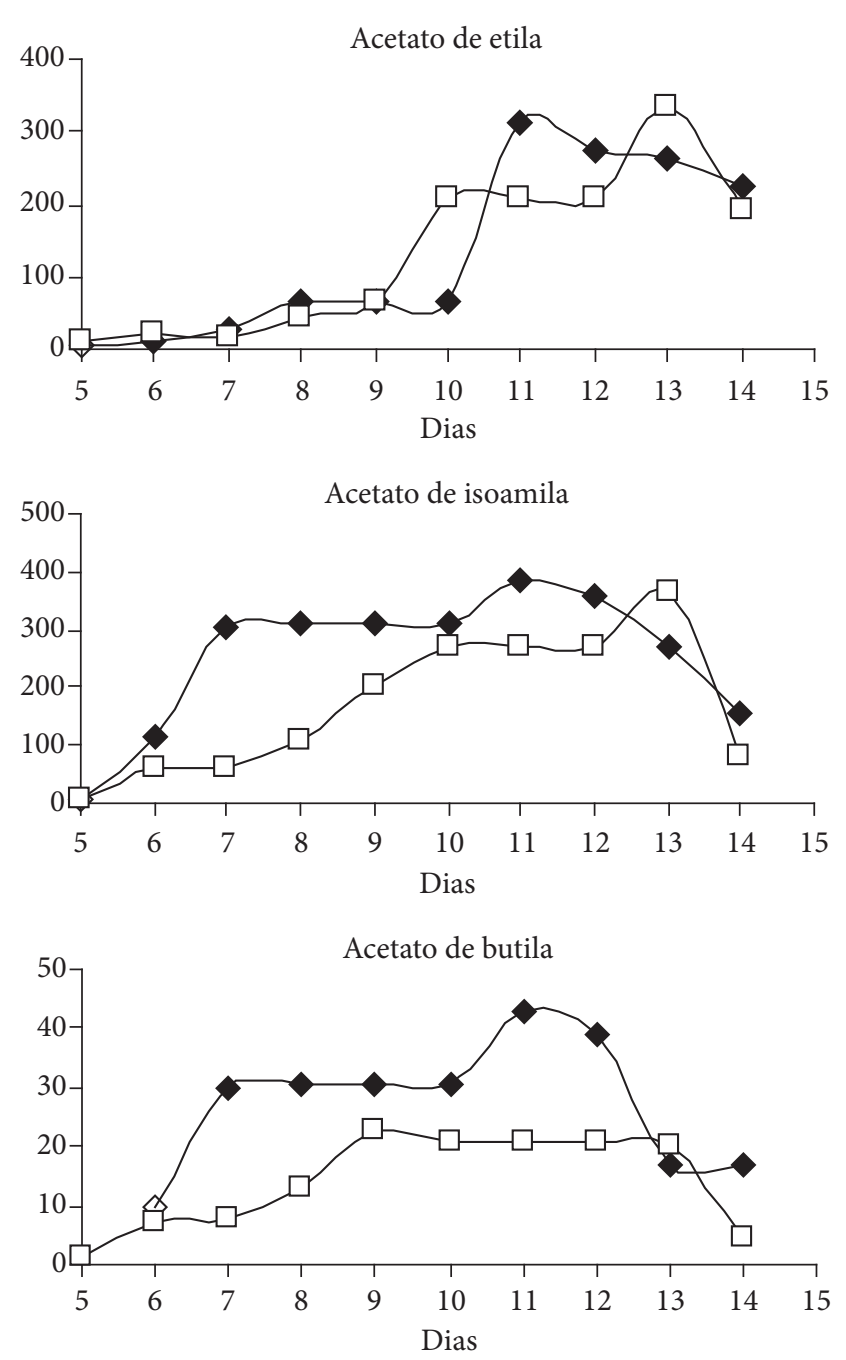

Acetato de isobutila

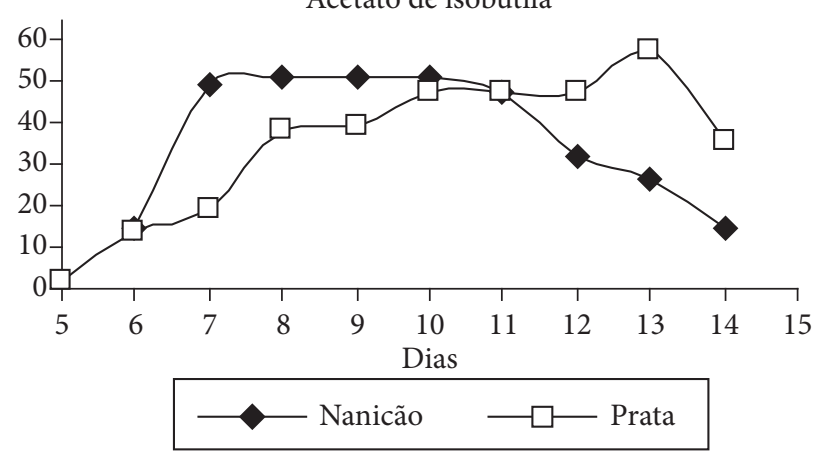

Figura 1. Produção dos ésteres acetato ( $\mu \mathrm{g} \cdot \mathrm{kg}^{-1}$ de polpa) durante o amadurecimento das cultivares de bananas Prata e Nanicão. Os valores de produção dos voláteis são a média de 3 repetições realizadas dia-a-dia $(\mathrm{X} \pm 2,51)$ para $\mathrm{p} \leq 0,05$.

no $5^{\circ}$ e no $6^{\circ}$ dia, com teores de aproximadamente $2 \mu \mathrm{g} . \mathrm{kg}^{-1}$, os quais desaparecem após esse período. Observaram-se ainda diferentes dias de surgimento do isobutirato de isoamila e de isobutila nas cultivares Prata e Nanicão. Enquanto que os isobutiratos de isoamila e isobutila são produzidos regularmente na banana Prata, na cultivar Nanicão começam a ser produzidos
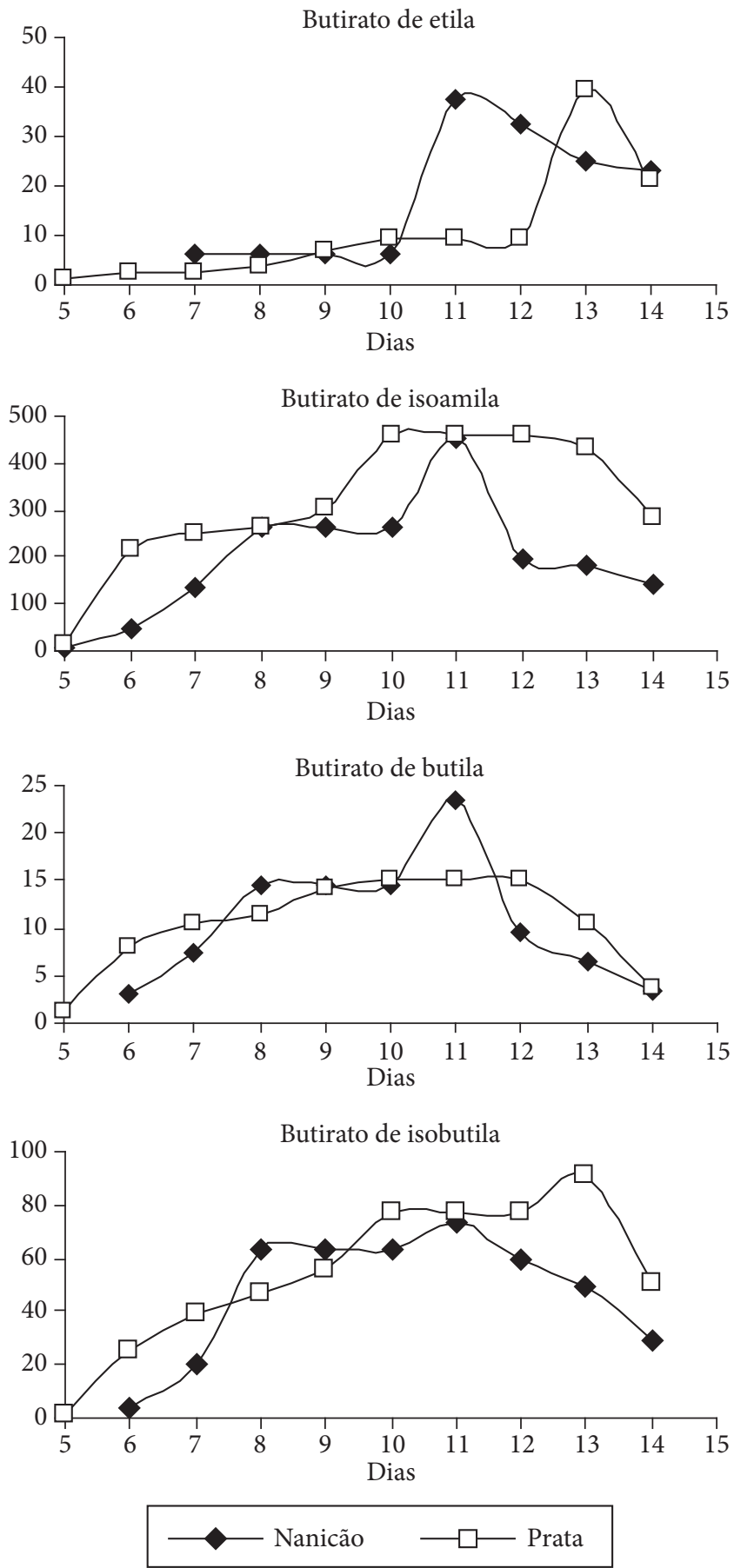

Figura 2. Produção dos ésteres butirato ( $\mu$ g. $\mathrm{kg}^{-1}$ de polpa) durante o amadurecimento das cultivares de bananas Prata e Nanicão. Os valores de produção dos voláteis são a média de 3 repetições realizadas dia-a-dia $(\mathrm{X} \pm 2,56)$ para $\mathrm{p} \leq 0,05$.

somente no $7^{\circ}$ e no $11^{\circ}$ dia, respectivamente. A maior concentração dos isobutiratos durante o amadurecimento foi encontrada para a cultivar Prata.

Na Figura 4 estão mostradas as variações na produção dos isovaleratos para as cultivares Prata e Nanicão durante o período do amadurecimento. Observaram-se diferenças significativas na produção dos ésteres entre as cultivares dia-a-dia. A exceção 

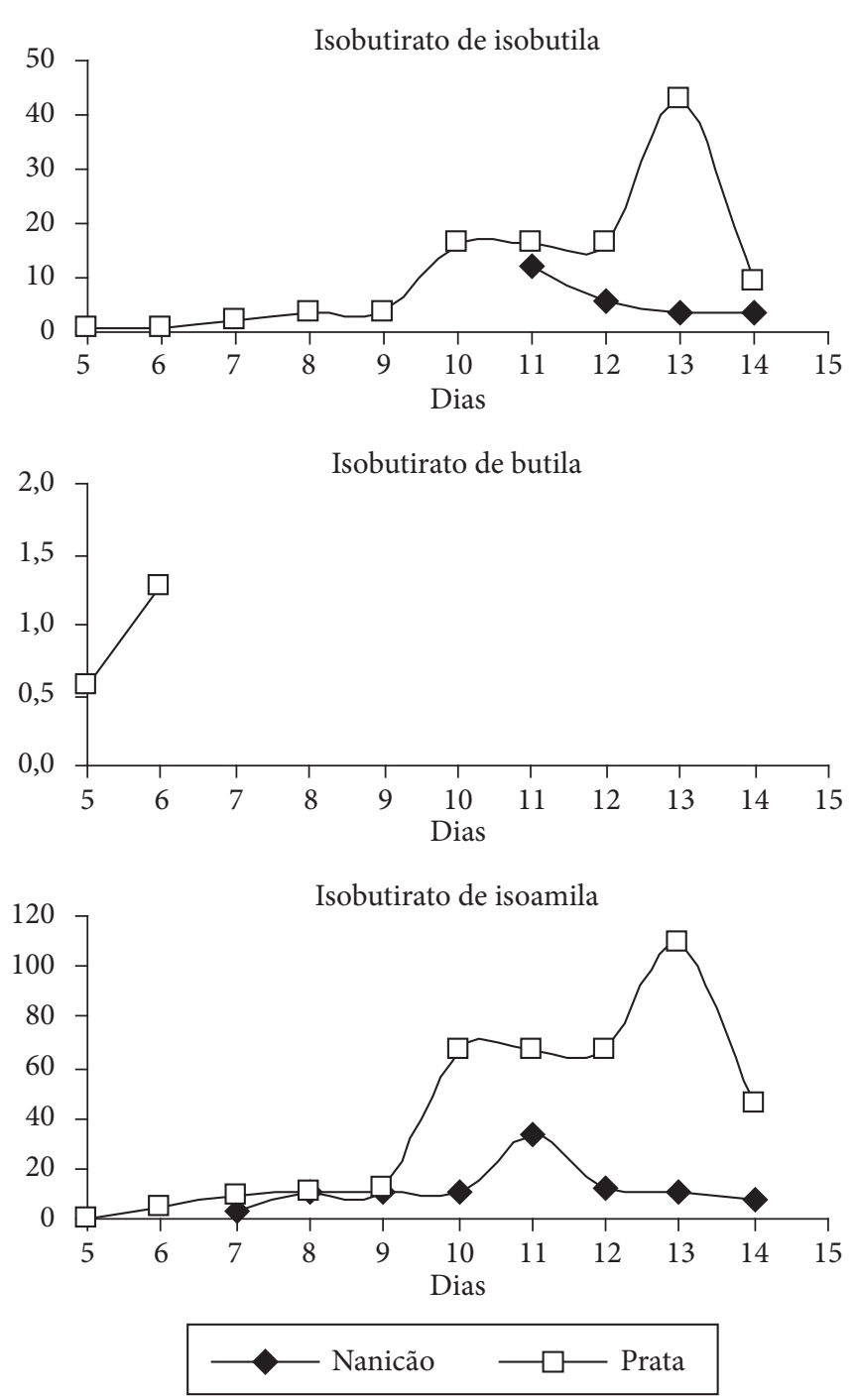

Figura 3. Produção dos ésteres isobutirato $\left(\mu \mathrm{g} . \mathrm{kg}^{-1} \mathrm{de}\right.$ polpa) durante o amadurecimento das cultivares de bananas Prata e Nanicão. Os valores de produção dos voláteis são a média de 3 repetições realizadas dia-a-dia $(X \pm 2,32)$ para $\mathrm{p} \leq 0,05$.

ocorreu no $8^{\circ}$, no $12^{\circ}$ e no $14^{\circ}$ dia para o isovalerato de etila e no $7^{\circ}$ e no $14^{\circ}$ dia para o isovalerato de isobutila. Como verificado para as outras classes de ésteres, ocorreram atrasos nos dias de surgimento dos isovaleratos. Enquanto que os isovaleratos de isoamila, isobutila, butila e etila são produzidos regularmente na cultivar Prata, estes ésteres só surgem na cultivar Nanicão a partir do $6^{\circ}, 7^{\circ}, 8^{\circ}$ e $13^{\circ}$ dias, respectivamente. $\mathrm{O}$ isovalerato de etila apresentou um comportamento particular na cultivar Nanicão, pois surge na fase de senescência, em que o fruto apresentou características de apodrecimento. A maior concentração dos isovaleratos durante o amadurecimento foi encontrada para a banana Prata. A exceção ficou por conta do isovalerato de butila, sendo que a banana Nanicão superou a Prata.

O comportamento das curvas de produção dos ésteres seguiu um aumento contínuo, até um pico, para em seguida apresentar uma diminuição gradativa até a senescência, semelhante aos resultados divulgados por Mattei (1973); Mattei e Paillard
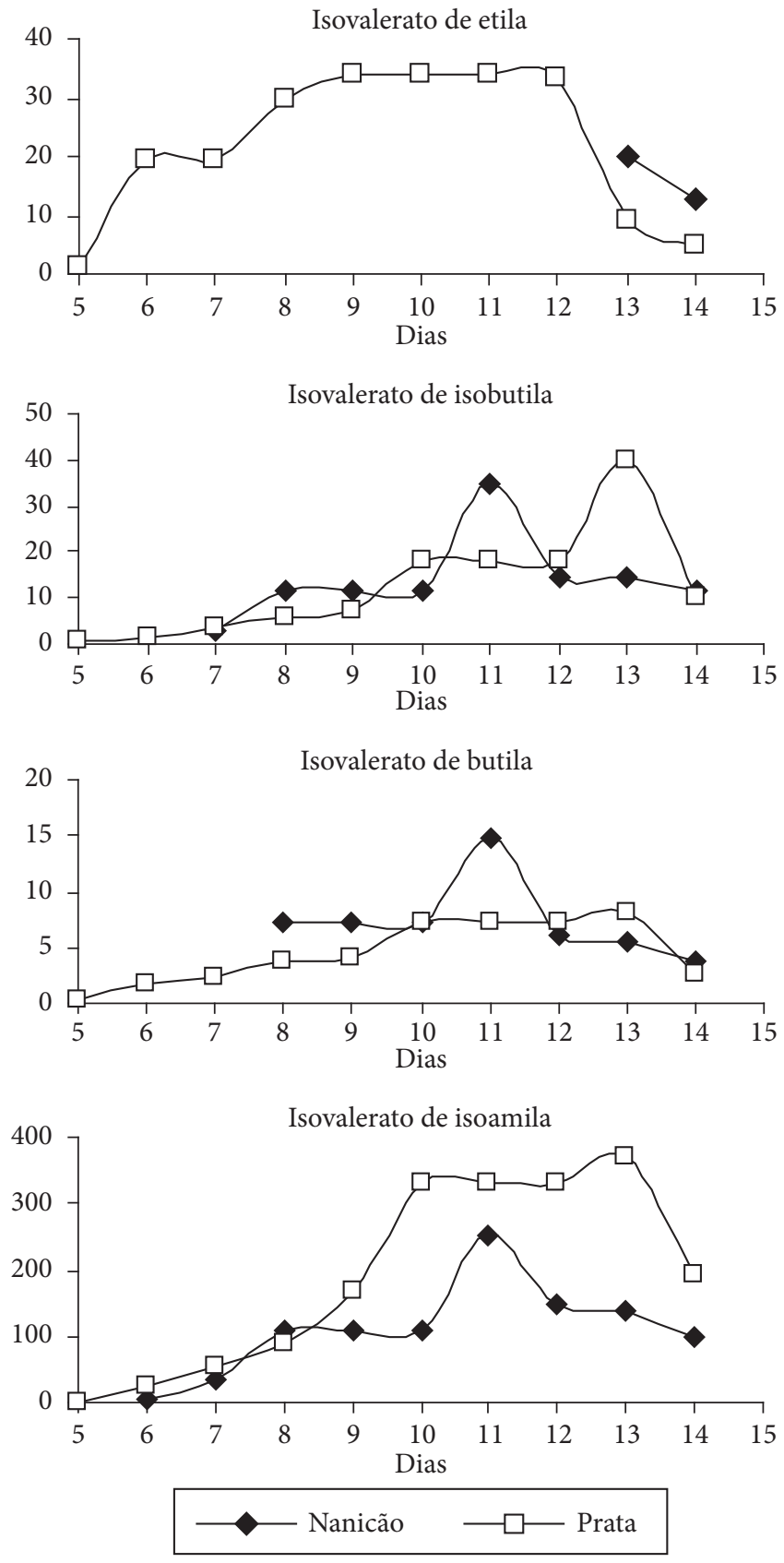

Figura 4. Produção dos ésteres isovalerato $\left(\mu \mathrm{g} . \mathrm{kg}^{-1}\right.$ de polpa) durante o amadurecimento das cultivares de bananas Prata e Nanicão. Os valores de produção dos voláteis são a média de 3 repetições realizadas dia-a-dia $(\mathrm{X} \pm 2,45)$ para $\mathrm{p} \leq 0,05$.

(1973) e Macku e Jennings (1987). A exceção para este comportamento são os ésteres isobutirato de isobutila e o isovalerato de etila na cultivar Nanicão e o isobutirato de butila na cultivar Prata. Ocorreu ainda uma forte queda na concentração para a maioria dos compostos voláteis após o período de crescimento, como também relatado nos trabalhos anteriores.

A queda no crescimento dos compostos voláteis ocorreu em dias diferentes para as cultivares. Enquanto que a banana Nanicão apresentou esta queda a partir do $12^{\circ}$ dia após a colheita, com exceção apenas para os ésteres acetato de isobutila 
e isovalerato de etila. A banana Prata exibiu para a maioria dos compostos voláteis queda no $14^{\circ}$ dia após a colheita, a exceção foram os ésteres acetato de butila, butirato de butila, butirato de isoamila e isovalerato de etila.

Esta queda para a banana Nanicão ( $12^{\circ}$ dia após a colheita) é semelhante ao descrito por Mattei (1973) e Mattei e Paillard (1973). Não foi observada uma taxa cíclica de produção para os ésteres acetato e butirato, conforme relatado no trabalho de Tressl e Jennings (1972).

A cultivar Prata apresentou globalmente uma maior concentração de compostos voláteis durante o amadurecimento, comparada à banana Nanicão, a exceção coube aos ésteres acetatos. Essa maior concentração de ésteres encontrados para a cultivar Prata pode estar associada aos maiores níveis em média de acidez encontrados para esta cultivar comparada à Nanicão, os quais são precursores de voláteis.

As quedas encontradas na produção dos compostos voláteis de bananas Prata e Nanicão, em diferentes estágios de maturação, podem também estar associadas aos eventos físico-químicos e bioquímicos, acontecendo em tempos diferentes para ambas as cultivares. Isto pode ter afetado o caminho metabólico dos precursores que leva à formação dos compostos voláteis, como os aminoácidos e os ácidos graxos, o que pode ter provocado as diferenças aqui observadas.

Segundo Golding et al. (1999), o declínio na formação dos compostos voláteis pode ser atribuído a fatores como a diminuição na concentração de precursores envolvidos na biossíntese destes ésteres que atuam como substrato nos processos do amadurecimento.

A combinação destes e de outros fatores podem responder pelas diferenças aqui encontradas para as cultivares Prata e Nanicão.

\section{Conclusões}

Dos resultados obtidos foi possível concluir que ocorreram diferenças físico-químicas significativas entre as cultivares Prata e Nanicão ao longo do processo de amadurecimento. A cultivar Nanicão apresentou um maior declínio nos valores de firmeza comparados à cultivar Prata. Ocorreu uma maior queda do $\mathrm{pH}$ para a cultivar Prata comparada à cultivar Nanicão. Observou-se uma maior concentração média de acidez para a cultivar Prata em relação à Nanicão. A cultivar Prata apresentou valores mais elevados de compostos fenólicos aos apresentados pela Nanicão. Observou-se um maior acúmulo de açúcares para a cultivar Prata comparada à Nanicão. Diferentes taxas de produção dos ésteres voláteis foram encontradas para as cultivares, sinalizando que o processo de amadurecimento dos frutos não é um sistema estático. Ao contrário, mostrou ser um sistema altamente dinâmico, com variações diárias. O método de extração dos voláteis por headspace em dedo frio se mostrou eficiente e preciso; servindo para monitorar o amadurecimento das cultivares de bananas aqui estudadas.

\section{Agradecimentos}

Os autores agradecem à Universidade Estadual do Sudoeste da Bahia - UESB, pela liberação do professor Baraquizio Braga do Nascimento Junior para o doutorado. Ao Programa de Qualificação Institucional da Capes - PQI, à Fundação de Apoio à Pesquisa do Estado do Rio de Janeiro - FAPERJ e ao CNPQ pelo apoio financeiro.

\section{Referências bibliográficas}

AOAC - ASSOCIATION OF OFFICIAL ANALYTICAL CHEMISTRY. Official methods of the association of official analytical chemistry. 12 ed. Washington, 1992.

AYRES, M. et al. BioEstat 2.0 - aplicações estatísticas nas áreas das ciências biológicas e médicas. 2 ed. Belém: Sociedade Civil Mamirauá; São Paulo: MCT; CNPq, 2000.

BLEINROTH, E. W. et al. Tecnologia pós-colheita de frutas tropicais. 1 ed. São Paulo: Instituto de Tecnologia de Alimentos, 1992.

BRITO, N. M. et al. Validação de métodos analíticos: estratégia e discussão. Revista Ecotoxicologia e Meio Ambiente, v. 13, p. 129-146, 2003.

CANO, M. P. et al. Differences among spanish and latin-american banana cultivars: morphological, chemical and sensory characteristics. Food Chemistry, v. 59, n. 3, p. 411-419, 1997.

GOLDING, J. B. et al. Relationships between respiration, ethylene, and aroma production in ripening banana. Journal of Agricultural and Food Chemistry, v. 47, n. 4, p. 1646-1651, 1999.

GOLDSTEIN, J. L.; SWAIN, T. Changes in tannis in ripening fruits. Phytochemistry, v. 2, p. 371-383, 1963.

IBÁÑEZ, E. et al. Analysis of volatile fruit components by headspace solid-phase microextraction. Food Chemistry, v. 63, n. 2, p. 281-286, 1998.

IBGE - Instituto Brasileiro de Geografia e Estatística. Disponível em: < http://www.sidra.ibge.gov.br>. Acesso em: 10 fev. 2007.

IMSABAI, W.; KETSA, S.; VAN DOORN, W. G. Physiological and biochemical changes during banana ripening and finger drop. Postharvest Biology Technology, v. 39, p. 211-216, 2006.

LICHTEMBERG, L. A. Banana: produção, colheita e pós - colheita. Informe Agropecuário, v. 20, n. 196, p. 73-90, 1999.

LOPES, D. C.; FRAGA, S. R.; REZENDE, C. M. Principais substâncias responsáveis pelo aroma de mangas comerciais brasileiras identificadas por cromatografia gasosa de alta resolução/ olfatometria/espectrometria de massas. Química Nova, v. 22, n. 1, p. 31-36, 1999.

MACKU, C.; JENNINGS, W. G. Production of volatiles by ripening bananas. Journal of Agricultural and Food Chemistry, v. 35, p. 845-848, 1987.

MATSUURA, F. C. A. U.; FOLEGATTI, M. I. S. Banana Pós - Colheita. 1 ed. Bahia: Embrapa Mandioca e Fruticultura, 2001.

MATTEI, A. Variations in the emission of volatiles from the banana, Musa cavendishii, in course of ripening and as a function of temperature. Physiologie Vegetale, v. 22, p. 721-738, 1973.

MATTEI, A.; PAILLARD, N. Analyse de l'emission volatiles de la banana. Fruits, v. 28, p. 231-238, 1973.

MIRANDA, E. J. F. et al. Odour-active compounds of banana passa identified by aroma extract dilution analysis. Flavour and Fragrance Journal, v. 16, n. 4, p. 281-285, 2001.

MOLLÁ, E. et al. Estudio de la determinación de azúcares em frutos e derivados. Alimentaria, v. 4, n. 254, p. 87-94, 1994. 
MORTON, I. D.; MACLEOD, A. J. Food Flavours. 1 ed. Amsterdam: Elsevier Science Publishers, 1990.

ONU - ORGANIZAÇÃO DAS NAÇÕES UNIDAS. Disponível em: < http://www.fao.org>. Acesso em: 05 nov. 2006.

PINHEIRO, A. C. M. Qualidade pós-colheita de banana 'maçã' submetida ao 1-mcp. Lavras, 2004. 60p. Dissertação - (Mestrado em Ciência de Alimentos), Departamento de Ciência dos alimentos, Universidade Federal de Lavras - UFLA.

RIBANI, M. et al. Validação em métodos cromatográficos e eletroforéticos. Química Nova, v. 27, n. 5, p. 771-780, 2004.
TRESSL, R.; JENNINGS, W. G. Production of volatiles compounds in the ripening banana. Journal of Agricultural and Food Chemistry, v. 20, n. 2, p. 189-192, 1972.

VAN DER KOOI, M. M. E.; NOIJ, T. H. M. Evaluation of solid-phase microextraction for the analysis of various priority pollutants in water. In: INTERNATIONAL SYMPOSIUM ON CAPILLARY CHROMATOGRAPHY, 16, 1994. Proceedings... Riva del Garda, Italy, sept. 27-30, p. 1087-1098, 1994.

VOGEL, A. I. Vogel's Textbook of Pratical Organic Chemistry. 5 ed. New York: John Wiley \& Sons, 1989.

WOOD, R. How to validate analytical methods. Trends in Analytical Chemistry, v. 18, n. 9-10, p. 624-632, 1999. 